\title{
Comparative Analysis of Anterior Segment Parameters in Normal and Keratoconus Eyes Generated by Scheimpflug Tomography
}

\author{
Faik Orucoglu ${ }^{1}$ and Ebru Toker ${ }^{2}$ \\ ${ }^{1}$ Birinci Eye Hospital, 34520 Istanbul, Turkey \\ ${ }^{2}$ Department of Ophthalmology, School of Medicine, Marmara University, 34782 Istanbul, Turkey \\ Correspondence should be addressed to Faik Orucoglu; faikorucov@yahoo.co.uk
}

Received 23 September 2014; Revised 7 January 2015; Accepted 16 February 2015

Academic Editor: Majid M. Moshirfar

Copyright ( 92015 F. Orucoglu and E. Toker. This is an open access article distributed under the Creative Commons Attribution License, which permits unrestricted use, distribution, and reproduction in any medium, provided the original work is properly cited.

Purpose. To assess and compare the anterior and posterior corneal surface parameters, keratoconus indices, thickness profile data, and data from enhanced elevation maps of keratoconic and normal corneas with the Pentacam Scheimpflug corneal tomography and to determine the sensitivity and specificity of these parameters in discriminating keratoconus from normal eyes. Methods. The study included 656 keratoconus eyes and 515 healthy eyes with a mean age of $30.95 \pm 9.25$ and $32.90 \pm 14.78$ years, respectively. Forty parameters obtained from the Pentacam tomography were assessed by the receiver operating characteristic curve analysis for their efficiency. Results. Receiver operating characteristic curve analyses showed excellent predictive accuracy (area under the curve, ranging from 0.914 to 0.972 ) for 21 of the 40 parameters evaluated. Among all parameters indices of vertical asymmetry, keratoconus index, front elevation at thinnest location, back elevation at thinnest location, Ambrósio Relational Thickness (ARTmax), deviation of average pachymetric progression, deviation of ARTmax, and total deviation showed excellent (>90\%) sensitivity and specificity in addition to excellent area under the receiver operating characteristic curve (AUROC). Conclusions. Parameters derived from the topometric and Belin-Ambrósio enhanced ectasia display maps very effectively discriminate keratoconus from normal corneas with excellent sensitivity and specificity.

\section{Introduction}

Keratoconus (KC) is a noninflammatory ectatic corneal dystrophy characterized by a usually progressive corneal thinning that results in corneal steepening, protrusion, irregular astigmatism, and gradual impairment of vision [1]. Although diagnosis of keratoconus is easy to determine with corneal topography, it is rather difficult to rule out subclinical KC before surgery. Detection of subclinical keratoconus or forme fruste keratoconus among refractive surgery candidates is important because keratorefractive procedures may worsen their condition. Placido disk-based topography systems are sensitive for detecting the subtle changes of topography on the anterior corneal surface. It provides accurate assessment of anterior corneal irregularities in the early stages of keratoconus. Keratoconus indices have been developed to help in detecting and staging keratoconus [2,3]. Diagnosis and classification criteria for $\mathrm{KC}$ are based on anterior corneal curvature data derived with Placido corneal topography. However, it was also reported that early changes in eyes with $\mathrm{KC}$ are also present on the posterior corneal surface $[4,5]$. Scheimpflug imaging provides the measurement of the entire cornea thickness by determining the front and back surfaces of the cornea taken by a rotating Scheimpflug camera. Keratoconic eyes have thinner corneas than normal eyes, with less volume and a more gradual increase in these parameters from the thinnest point toward the periphery [6]. The combination of the pachymetric graphs and the enhanced elevation maps provided by the Belin-Ambrósio enhanced ectasia display (BAD) of the Scheimpflug system shows sensitivity and specificity in the screening of patients for forme fruste keratoconus eyes [7]. 
Evaluation of keratoconic and normal eyes to determine all tomographic parameters including keratoconus indices, pachymetric graph values, and back difference elevation values of the corneas may help to identify at-risk corneas.

The purpose of our study was to evaluate and compare the anterior and posterior corneal surface parameters, keratoconus indices, thickness profile data, and data from enhanced elevation maps of keratoconic and normal corneas with the Pentacam Scheimpflug corneal tomography and to determine the sensitivity and specificity of these parameters in discriminating keratoconus from normal eyes.

\section{Patients and Methods}

The protocol of this retrospective clinic-based observational study of 656 eyes of 338 patients diagnosed with keratoconus and 513 eyes of 268 healthy control subjects adhered to the tenets of the Declaration of Helsinki and was approved by the Ethics Committee, Marmara University Hospital, Istanbul, Turkey. All patients included in the study were informed about the purpose of the study and provided informed consent. Subjects were recruited from consecutive patients who were admitted to the university hospital (Marmara University Hospital, Istanbul, Turkey) or the private eye hospital (Birinci Eye Hospital, Istanbul, Turkey) for ocular examination between September 2013 and April 2014.

Exclusion criteria were previous eye trauma, corneal or intraocular surgery, glaucoma, corneal scarring, severe eye dryness, pregnancy or nursing, current corneal infections, and the use of topical medications. Soft contact lens users were included in the study after discontinuation of lens wear for at least 7 days.

Keratoconus was diagnosed mainly on the basis of clinical slit-lamp findings, keratometry, and associated characteristic topographic patterns. Eyes were considered normal if they had no ocular pathology, no previous ocular surgery, and no irregular corneal pattern.

A comprehensive ocular examination including Scheimpflug corneal tomography was performed on all eyes. Measurements were taken with a high-resolution imaging system which uses a rotating Scheimpflug camera (Pentacam, Oculus Optikgeräte $\mathrm{GmbH}$, Wetzlar, Germany) and a monochromatic slit-light source that rotate together around the optical axes of the eye for measuring anterior segment topography. The Pentacam provides a multitude of corneal topographic (keratometric), topometric, tomographic, and pachymetric data. The room lights were switched off for all examinations to get a reflex-free image. The subjects were asked to position themselves, blink a couple of times, and fixate on the black target in the center of the blue fixation beam. Patients were instructed to close their eyes between shots for at least 10 seconds to moisten the eyes. The images were obtained with the automatic mode. The camera was rotated $180^{\circ}$, obtaining 25 slit images of the anterior segment, and generated a three-dimensional model of the anterior eye. Eye movement of the subject was constantly monitored by the system, and quality factor was automatically evaluated. Only the scan results with quality factor (QS) of $>95 \%$ were saved.
Parameters were derived from topographic, topometric, and BAD maps (Figures 1(a), 1(b), and 1(c)). Parameters of the printout retained for the analysis were keratometry readings, topographic astigmatism and asphericity for the anterior and posterior corneal surface, pachymetry, cornea volume, and anterior chamber volume, angle, and depth, topometric indices, data from corneal thickness spatial profiles, and Belin-Ambrósio enhanced ectasia display. The abbreviations for these parameters are used in this paper and they are explained in Abbreviations.

Corneal thickness was defined as the thinnest point in the corneal thickness map. Corneal volume is reported as the volume of the cornea in a diameter of $10 \mathrm{~mm}$, centered on the anterior corneal apex. Anterior chamber depth was defined as the distance from the corneal endothelium to the anterior surface of the lens capsule. The anterior chamber volume is calculated from endothelium down to iris and lens over a $12 \mathrm{~mm}$ diameter centered on the anterior corneal apex. The default angle displayed is the smallest angle in the horizontal position calculated from the Scheimpflug image. For elevation data measurement, the best fit sphere served as a reference body using the float option and the diameter of the reference surface was $8 \mathrm{~mm}$. Front and back elevation difference values were taken as the differential changes in corneal elevation between the best fit sphere (BFS) and the enhanced BFS obtained with the BAD display software. Progression index is calculated as the average progression value at the different pachymetric rings, referenced to the mean curve.

Spherical equivalent (SE: sphere + half the cylinder) values, in diopters (D), were calculated from cycloplegic refraction for each patient. The asphericity data provided by the Pentacam was taken from $8 \mathrm{~mm}$ central cornea with reference to the anterior corneal apex.

Eyes with keratoconus were compared with normal corneas in separate series of analyses. All numerical results were entered into a database, and statistical analysis was performed using Statistical Package for Social Sciences (SPSS) version 16.0. ROC curves were used to determine the overall predictive accuracy of the test as described by the area under the curve. For the output values of the discriminant functions tested, the area under the ROC curve (AUROC), sensitivity (true positive/(true positive false negative)), specificity (true negative/(true negative false positive)), accuracy ((true positive true negative)/total number of cases), and cutoff value were calculated.

The AUROC curve is a plot of sensitivity against 1 specificity, that is, true positives versus false positives. This area ranges from $1(100 \%)$ representing perfect discrimination to $0.5(50 \%)$ representing discrimination being no better than chance. In between that range, 0.90-1 represent excellent discrimination, $0.80-0.90$ good, $0.70-0.80$ fair, $0.60-0.70$ poor, and $0.50-0.60$ very poor [8]. An area of 0.5 represents a completely inefficient measure.

\section{Results}

In the normal group, the study involved 513 eyes of 268 subjects with a mean age of 32.99 years, ranging from 8 to 


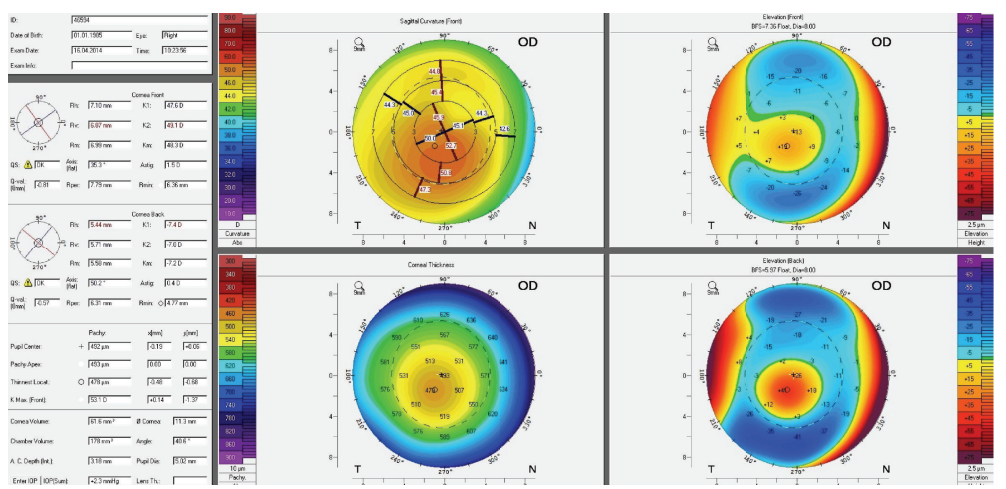

(a)
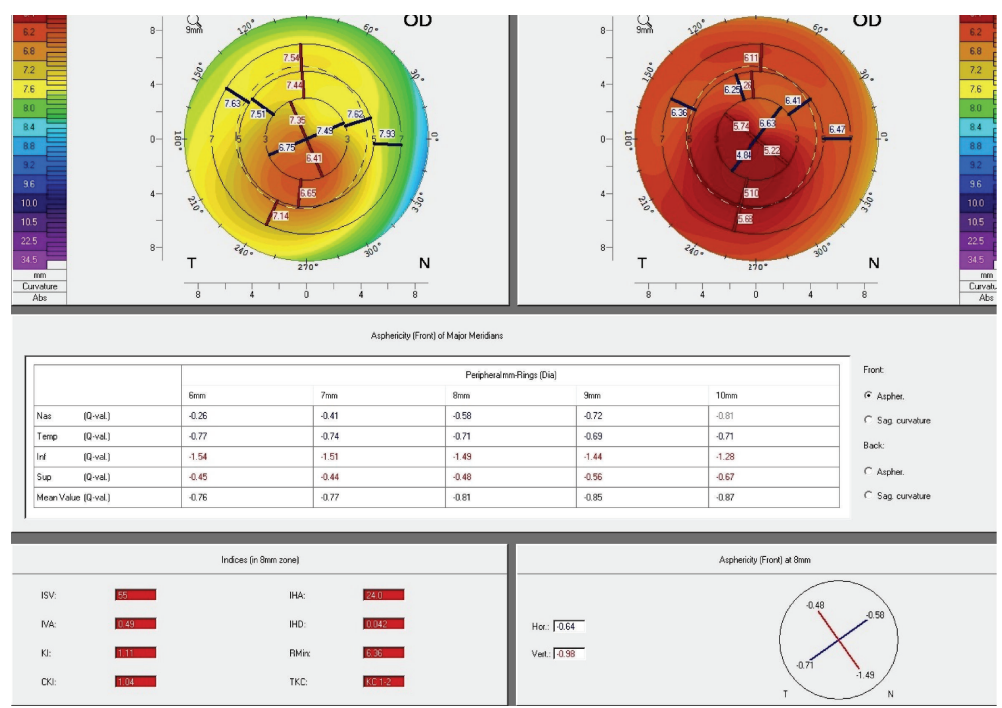

(b)
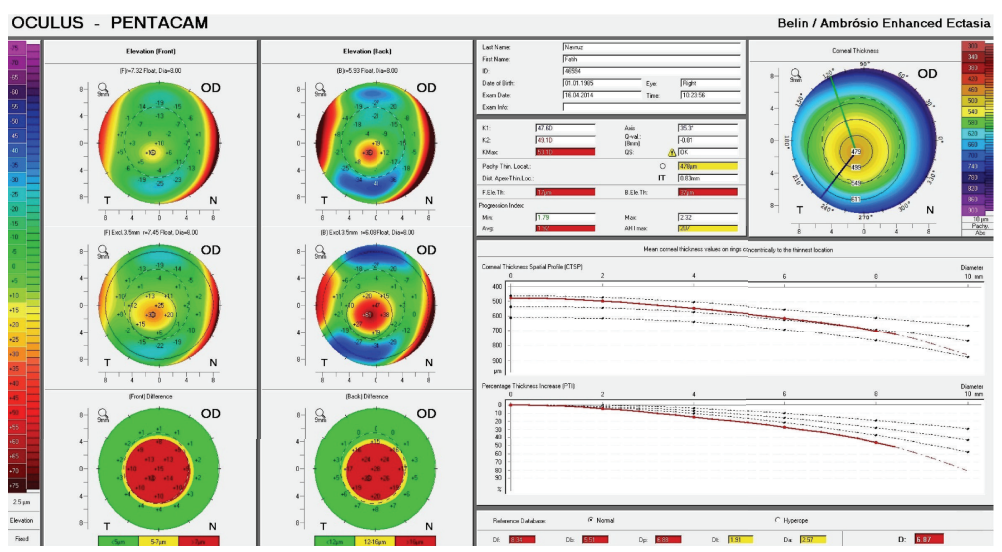

(c)

Figure 1: (a) Topographic, (b) topometric, and (c) Belin-Ambrósio enhanced ectasia display maps of the Pentacam.

74 years old. One hundred nine (48.1\%) of subjects were male and 139 (51.9\%) were female. In the keratoconus group, the study involved 656 eyes of 338 subjects with a mean age of 31.18 years, ranging from 13 to 64 years old. Two hundred fourteen (63.2\%) of subjects were male and 124 (36.8\%) were female. The mean spherical refraction of normal eyes was $-0.88 \mathrm{D}$.
The two groups did not differ significantly with regard to age and gender $(P=0.086$ and $P=0.09$, resp. $)$.

The mean Pentacam parameters and the differences between keratoconus and normal subjects are shown in Table 1.

All parameters derived from the three maps showed statistically significant difference between keratoconic and 
TABle 1: Mean Pentacam parameters and the difference between keratoconus and normal eyes.

\begin{tabular}{|c|c|c|c|}
\hline Pentacam parameter & $\begin{array}{c}\text { KC } \\
\text { Mean } \pm \text { SD } \\
\text { (range) }\end{array}$ & $\begin{array}{c}\text { Control } \\
\text { Mean } \pm \text { SD } \\
\text { (range) }\end{array}$ & $P$ \\
\hline \multicolumn{4}{|l|}{ Topographic map } \\
\hline Kflat (Ant.) & $\begin{array}{c}46.37 \pm 4.75 \\
(38.40-72.60)\end{array}$ & $\begin{array}{c}43.03 \pm 1.57 \\
(38.90-47.70)\end{array}$ & $<0.001$ \\
\hline Ksteep (Ant.) & $\begin{array}{c}49.41 \pm 5.56 \\
(40.30-82.10)\end{array}$ & $\begin{array}{c}44.17 \pm 1.58 \\
(40.10-49.40)\end{array}$ & $<0.001$ \\
\hline Kmean (Ant.) & $\begin{array}{l}47.80 \pm 5.06 \\
(39.50-77.10)\end{array}$ & $\begin{array}{c}43.60 \pm 1.52 \\
(39.70-48.00)\end{array}$ & $<0.001$ \\
\hline $\mathrm{Kmax}$ & $\begin{array}{c}54.11 \pm 8.34 \\
(42.10-110.50)\end{array}$ & $\begin{array}{c}44.67 \pm 2.17 \\
(12.30-50.20)\end{array}$ & $<0.001$ \\
\hline Astigmatism (Ant.) & $\begin{array}{c}3.05 \pm 1.97 \\
(0.00-17.00)\end{array}$ & $\begin{array}{l}1.13 \pm 0.86 \\
(0.00-6.10)\end{array}$ & $<0.001$ \\
\hline Asphericity (Ant.) & $\begin{array}{l}-0.78 \pm 0.54 \\
(-6.90-0.17)\end{array}$ & $\begin{array}{c}-0.34 \pm 0.12 \\
(0.83-0.30)\end{array}$ & $<0.001$ \\
\hline Kflat (Post.) & $\begin{array}{l}-6.82 \pm 0.96 \\
(-11.90-5.00)\end{array}$ & $\begin{array}{l}-6.13 \pm 0.26 \\
(-7.00-5.30)\end{array}$ & $<0.001$ \\
\hline Ksteep (Post.) & $\begin{array}{c}-7.39 \pm 1.08 \\
(-13.50-0.50)\end{array}$ & $\begin{array}{c}-6.41 \pm 0.28 \\
(-7.40-5.70)\end{array}$ & $<0.001$ \\
\hline Kmean (Post.) & $\begin{array}{l}-7.09 \pm 0.95 \\
(-12.50-5.30)\end{array}$ & $\begin{array}{c}-6.27 \pm 0.24 \\
(-7.00-5.50)\end{array}$ & $<0.001$ \\
\hline Astigmatism (Post.) & $\begin{array}{l}0.71 \pm 0.44 \\
(0.00-4.40)\end{array}$ & $\begin{array}{c}0.31 \pm 0.17 \\
(-0.30-1.00)\end{array}$ & $<0.001$ \\
\hline Asphericity (Post.) & $\begin{array}{l}-0.81 \pm 0.52 \\
(-3.79-0.89)\end{array}$ & $\begin{array}{c}0.35 \pm 0.15 \\
(-0.90-0.19)\end{array}$ & $<0.001$ \\
\hline TCT & $\begin{array}{c}456.76 \pm 54.53 \\
\quad(171-626)\end{array}$ & $\begin{array}{c}545.94 \pm 36.76 \\
\quad(443-656)\end{array}$ & $<0.001$ \\
\hline Cornea Vol & $\begin{array}{c}57.08 \pm 3.71 \\
(47.20-70.60)\end{array}$ & $\begin{array}{c}60.70 \pm 4.06 \\
(49.80-75.60)\end{array}$ & $<0.001$ \\
\hline AC Vol & $\begin{array}{c}195.90 \pm 35.12 \\
\quad(100-287)\end{array}$ & $\begin{array}{c}175.04 \pm 42.37 \\
(63.00-289)\end{array}$ & $<0.001$ \\
\hline $\mathrm{ACD}$ & $\begin{array}{l}3.32 \pm 0.35 \\
(1.96-4.75)\end{array}$ & $\begin{array}{r}3.00 \pm 0.41 \\
(1.81-4.18)\end{array}$ & $<0.001$ \\
\hline AC Angle & $\begin{array}{c}39.20 \pm 6.59 \\
(16.90-66.90)\end{array}$ & $\begin{array}{c}37.01 \pm 8.13 \\
(4.86-73.30)\end{array}$ & $<0.001$ \\
\hline \multicolumn{4}{|l|}{ Topometric map } \\
\hline ISV & $\begin{array}{c}76.10 \pm 42.42 \\
(10-289)\end{array}$ & $\begin{array}{l}17.70 \pm 6.67 \\
(5.00-52.00)\end{array}$ & $<0.001$ \\
\hline IVA & $\begin{array}{l}0.77 \pm 0.44 \\
(0.02-2.44)\end{array}$ & $\begin{array}{c}0.12 \pm 0.058 \\
(0.01-0.42)\end{array}$ & $<0.001$ \\
\hline $\mathrm{KI}$ & $\begin{array}{l}1.19 \pm 0.13 \\
(1.00-2.11)\end{array}$ & $\begin{array}{r}1.01 \pm 0.019 \\
(0.95-1.07)\end{array}$ & $<0.001$ \\
\hline CKI & $\begin{array}{r}1.05 \pm 0.057 \\
(0.90-1.37)\end{array}$ & $\begin{array}{c}1.00 \pm 0.005 \\
(0.97-1.02)\end{array}$ & $<0.001$ \\
\hline IHA & $\begin{array}{c}22.64 \pm 18.96 \\
(0.20-131.90)\end{array}$ & $\begin{array}{c}4.13 \pm 4.60 \\
(0.00-28.60)\end{array}$ & $<0.001$ \\
\hline IHD & $\begin{array}{r}0.75 \pm 0.070 \\
(0.00-0.67)\end{array}$ & $\begin{array}{c}0.011 \pm 0.019 \\
(0.00-0.24)\end{array}$ & $<0.001$ \\
\hline Rmin & $\begin{array}{l}6.35 \pm 0.81 \\
(3.05-8.02)\end{array}$ & $\begin{array}{l}7.55 \pm 0.27 \\
(6.72-8.37)\end{array}$ & $<0.001$ \\
\hline HOR Q & $\begin{array}{c}-0.85 \pm 1.50 \\
(-37-0.28)\end{array}$ & $\begin{array}{l}-0.33 \pm 0.14 \\
(-0.88-0.36)\end{array}$ & $<0.001$ \\
\hline VERT Q & $\begin{array}{c}-1.01 \pm 3.66 \\
(-69-1.78)\end{array}$ & $\begin{array}{l}-0.35 \pm 0.16 \\
(-0.96-0.29)\end{array}$ & $<0.001$ \\
\hline
\end{tabular}

TABLE 1: Continued.

\begin{tabular}{|c|c|c|c|}
\hline Pentacam parameter & $\begin{array}{c}\text { KC } \\
\text { Mean } \pm \text { SD } \\
\text { (range) }\end{array}$ & $\begin{array}{l}\text { Control } \\
\text { Mean } \pm \text { SD } \\
\text { (range) }\end{array}$ & $P$ \\
\hline \multicolumn{4}{|l|}{ BAD display } \\
\hline Front diff. & $\begin{array}{c}16.28 \pm 12.14 \\
(-4.00-96)\end{array}$ & $\begin{array}{c}3.59 \pm 2.43 \\
(-5.00-8.00)\end{array}$ & $<0.001$ \\
\hline Back diff. & $\begin{array}{c}35.74 \pm 25.95 \\
(0.00-217)\end{array}$ & $\begin{array}{c}5.64 \pm 3.50 \\
(-3.00-20.00)\end{array}$ & $<0.001$ \\
\hline Dist.Apex-Th & $\begin{array}{c}0.84 \pm 0.28 \\
(0.13-2.79)\end{array}$ & $\begin{array}{r}0.82 \pm 0.23 \\
(0.18-1.63)\end{array}$ & 0.349 \\
\hline F.Ele.Th & $\begin{array}{c}20.53 \pm 14.33 \\
(-7.00-112)\end{array}$ & $\begin{array}{c}2.29 \pm 1.80 \\
(-6.00-8.00)\end{array}$ & $<0.001$ \\
\hline B.Ele.Th & $\begin{array}{c}47.39 \pm 28.52 \\
(1.00-202)\end{array}$ & $\begin{array}{c}6.41 \pm 3.83 \\
(-2.00-28.00)\end{array}$ & $<0.001$ \\
\hline ProgMin & $\begin{array}{c}1.74 \pm 1.11 \\
(0.28-11.52)\end{array}$ & $\begin{array}{l}0.69 \pm 0.12 \\
(0.14-1.25)\end{array}$ & $<0.001$ \\
\hline ProgMax & $\begin{array}{l}3.20 \pm 3.24 \\
(0.91-50.58)\end{array}$ & $\begin{array}{l}1.22 \pm 0.20 \\
(0.75-2.20)\end{array}$ & $<0.001$ \\
\hline ProgAvg & $\begin{array}{c}2.26 \pm 1.88 \\
(0.74-24.63)\end{array}$ & $\begin{array}{l}0.96 \pm 0.13 \\
(0.65-1.63)\end{array}$ & $<0.001$ \\
\hline ARTmax & $\begin{array}{c}187.74 \pm 91.00 \\
(1.45-567)\end{array}$ & $\begin{array}{l}457.83 \pm 86.44 \\
\quad(120-725)\end{array}$ & $<0.001$ \\
\hline Df & $\begin{array}{c}9.63 \pm 8.62 \\
(-1.16-64.58)\end{array}$ & $\begin{array}{c}0.22 \pm 1.14 \\
(-1.85-8.93)\end{array}$ & $<0.001$ \\
\hline $\mathrm{Db}$ & $\begin{array}{c}8.34 \pm 10.57 \\
(-1.00-163.11)\end{array}$ & $\begin{array}{c}0.04 \pm 0.91 \\
(-1.47-3.94)\end{array}$ & $<0.001$ \\
\hline $\mathrm{Dp}$ & $\begin{array}{c}9.13 \pm 12.29 \\
(-1.10-160.47)\end{array}$ & $\begin{array}{c}0.35 \pm 1.89 \\
(-37.00-6.69)\end{array}$ & $<0.001$ \\
\hline $\mathrm{Dt}$ & $\begin{array}{c}3.02 \pm 2.90 \\
(-2.17-32.99)\end{array}$ & $\begin{array}{l}-0.15 \pm 1.02 \\
(-2.68-3.18)\end{array}$ & $<0.001$ \\
\hline $\mathrm{Da}$ & $\begin{array}{c}2.72 \pm 0.81 \\
(-0.72-4.42)\end{array}$ & $\begin{array}{l}0.27 \pm 0.77 \\
(-2.16-2.33)\end{array}$ & $<0.001$ \\
\hline $\mathrm{D}$ & $\begin{array}{c}8.39 \pm 6.22 \\
(0.36-71.96)\end{array}$ & $\begin{array}{c}0.93 \pm 0.66 \\
(-0.79-3.85)\end{array}$ & $<0.001$ \\
\hline
\end{tabular}

normal eyes except the distance from corneal apex to thinnest location parameter $(P=0.349)$.

Table 2 shows the results of the ROC curve analysis, standard error, 95\% confidence intervals, significance level, best cutoff point, and sensitivity and specificity of best cutoff points for each parameter tested in keratoconus group versus normal eyes.

Out of 40 parameters derived from the topographic, topometric, and BAD maps 2 (TCT, AUROC 0.915; Kmax, AUROC 0.928), 5 (ISV, AUROC 0.954; IVA, AUROC 0.963; KI, AUROC 0.970; IHD, AUROC 0.951; Rmin, AUROC 0.929), and 14 (FDE, AUROC 0.910 BDE, AUROC 0.954; F.Ele.Th, AUROC 0.959; B.Ele.Th, AUROC 0.967; ProgMin, AUROC 0.935; ProgMax, AUROC 0.964; ProgAvg, AUROC 0.955; ARTmac, AUROC 0.961; Df, AUROC 0.949; Db, AUROC 0.957; Dp, AUROC 0.954; Dt, AUROC 0.914; Da, AUROC 0.964; D, AUROC 0.972) parameters, respectively, showed excellent AUROC values in discriminating keratoconic eyes from normal ones.

Among these parameters IVA, KI, F.Ele.Th, B.Ele.Th, ARTmac, Dp, Da, and D showed excellent (>90\%) sensitivity 
TABLE 2: ROC curve analysis for the keratoconus eyes versus normal eyes.

\begin{tabular}{|c|c|c|c|c|c|c|c|}
\hline Parameters & AUC & SE & $95 \% \mathrm{CI}$ & $P$ & Cutoff & Sensitivity & Specificity \\
\hline \multicolumn{8}{|l|}{ Topographic map } \\
\hline Kflat (Ant.) & 0.755 & 0.014 & $0.728-0.783$ & $<0.001$ & 45.15 & 0.500 & 0.915 \\
\hline Ksteep (Ant.) & 0.857 & 0.011 & $0.836-0.878$ & $<0.001$ & 46.45 & 0.685 & 0.929 \\
\hline Kmean (Ant.) & 0.820 & 0.012 & $0.796-0.844$ & $<0.001$ & 45.25 & 0.646 & 0.863 \\
\hline \multicolumn{8}{|l|}{ Kmax } \\
\hline Astigmatism (Ant.) & 0.815 & 0.013 & $0.791-0.840$ & $<0.001$ & 1.65 & 0.733 & 0.816 \\
\hline Asphericity (Ant.) & 0.795 & 0.014 & $0.768-0.721$ & $<0.001$ & -0.565 & 0.974 & 0.618 \\
\hline Kflat (Post.) & 0.757 & 0.014 & $0.729-0.785$ & $<0.001$ & -6.55 & 0.939 & 0.516 \\
\hline Ksteep (Post.) & 0.842 & 0.012 & $0.819-0.865$ & $<0.001$ & -6.85 & 0.941 & 0.674 \\
\hline Kmean (Post.) & 0.819 & 0.012 & $0.795-8.44$ & $<0.001$ & -6.65 & 0.945 & 0.631 \\
\hline Kmax & 0.928 & 0.008 & $0.914-0.943$ & $<0.001$ & 47.05 & 0.839 & 0.935 \\
\hline Astigmatism (Post.) & 0.802 & 0.013 & $0.776-0.828$ & $<0.001$ & 0.45 & 0.708 & 0.828 \\
\hline Asphericity (Post.) & 0.780 & 0.014 & $0.752-0.807$ & $<0.001$ & -0.555 & 0.892 & 0.678 \\
\hline TCT & 0.915 & 0.08 & $0.899-0.932$ & $<0.001$ & 506.5 & 0.890 & 0.832 \\
\hline Cornea Vol & 0.713 & 0.015 & $0.701-0.760$ & $<0.001$ & 58.55 & 0.695 & 0.687 \\
\hline AC Vol & 0.650 & 0.017 & $0.617-0.683$ & $<0.001$ & 169.5 & 0.769 & 0.452 \\
\hline $\mathrm{ACD}$ & 0.724 & 0.015 & $0.695-0.754$ & $<0.001$ & 3.155 & 0.703 & 0.631 \\
\hline AC Angle & 0.584 & 0.017 & $0.550-0.618$ & $<0.001$ & 33.25 & 0.854 & 0.278 \\
\hline \multicolumn{8}{|l|}{ Topometric map } \\
\hline ISV & 0.954 & 0.006 & $0.942-0.966$ & $<0.001$ & 31.5 & 0.878 & 0.962 \\
\hline IVA & 0.963 & 0.006 & $0.952-0.974$ & $<0.001$ & 0.255 & 0.913 & 0.964 \\
\hline KI & 0.970 & 0.005 & $0.960-0.979$ & $<0.001$ & 1.055 & 0.910 & 0.982 \\
\hline CKI & 0.824 & 0.013 & $0.798-0.849$ & $<0.001$ & 1.015 & 0.727 & 0.982 \\
\hline IHA & 0.883 & 0.10 & $0.863-0.902$ & $<0.001$ & 8.65 & 0.757 & 0.886 \\
\hline IHD & 0.951 & 0.006 & $0.938-0.963$ & $<0.001$ & 0.0175 & 0.900 & 0.890 \\
\hline Rmin & 0.929 & 0.008 & $0.914-0.943$ & $<0.001$ & 7.085 & 0.968 & 0.807 \\
\hline HOR Q & 0.811 & 0.13 & $0.895-0.837$ & $<0.001$ & -0.495 & 0.896 & 0.711 \\
\hline VERT Q & 0.719 & 0.015 & $0.689-0.750$ & $<0.001$ & -0.625 & 0.951 & 0.545 \\
\hline \multicolumn{8}{|l|}{ BAD maps } \\
\hline Front diff. & 0.910 & 0.008 & $0.894-0.926$ & $<0.001$ & 8.5 & 0.716 & 1 \\
\hline Back diff. & 0.954 & 0.006 & $0.942-0.966$ & $<0.001$ & 12.5 & 0.873 & 0.961 \\
\hline Dist.Apex-Th & 0.512 & 0.17 & $0.478-0.545$ & 0.499 & 0.955 & 0.314 & 0.760 \\
\hline F.Ele.Th & 0.959 & 0.006 & 0.947-0971 & $<0.001$ & 5.5 & 0.913 & 0.974 \\
\hline B.Ele.Th & 0.967 & 0.005 & $0.956-0.977$ & $<0.001$ & 13.5 & 0.932 & 0.949 \\
\hline ProgMin & 0.935 & 0.008 & $0.921-0.950$ & $<0.001$ & 0.925 & 0.854 & 0.972 \\
\hline ProgMax & 0.964 & 0.005 & $0.953-0.974$ & $<0.001$ & 1.675 & 0.888 & 0.978 \\
\hline ProgAvg & 0.955 & 0.006 & $0.943-0.968$ & $<0.001$ & 1.185 & 0.914 & 0.951 \\
\hline ARTmax & 0.961 & 0.006 & $0.949-0.972$ & $<0.001$ & 311 & 0.966 & 0.907 \\
\hline Df & 0.949 & 0.006 & $0.937-0.962$ & $<0.001$ & 2.575 & 0.847 & 0.972 \\
\hline $\mathrm{Db}$ & 0.957 & 0.006 & $0.946-0.968$ & $<0.001$ & 1.72 & 0.882 & 0.943 \\
\hline $\mathrm{Dp}$ & 0.954 & 0.006 & $0.942-0.967$ & $<0.001$ & 1.855 & 0.919 & 0.951 \\
\hline $\mathrm{Dt}$ & 0.914 & 0.008 & $0.897-0.930$ & $<0.001$ & 0.955 & 0.830 & 0.888 \\
\hline $\mathrm{Da}$ & 0.964 & 0.006 & $0.953-0.975$ & $<0.001$ & 1.62 & 0.905 & 0.968 \\
\hline $\mathrm{D}$ & 0.972 & 0.005 & $0.963-0.982$ & $<0.001$ & 2.615 & 0.932 & 0.990 \\
\hline
\end{tabular}

AUC: Area Under ROC Curve.

SE: Standard error.

CI: Confidence Interval.

$P$ : Probability. 
TABLE 3: Abnormal topometric indices values of the manufacturer's user manual and the study.

\begin{tabular}{lcc}
\hline Index & Abnormal values of manufacturer's user manual & Abnormal values of the study \\
\hline ISV & & $>31.5$ \\
IVA & 0.28 & $>0.255$ \\
KI & $>1.07$ & $>1.055$ \\
CKI & 1.03 & $>1.015$ \\
IHA & 19 & $>8.65$ \\
IHD & 0.014 & $>0.0175$ \\
Rmin & $<6.71$ & $<7.085$ \\
\hline
\end{tabular}

and specificity in addition to excellent AUROC. The cutoff points derived from the ROC curve analysis were 0.255 for IVA, 1.055 for KI, 5.5 for F.Ele.Th, 13.5 for B.Ele.Th, 311 for ARTmac, 1.855 for Dp, 1.62 for $\mathrm{Da}$, and 2.615 for D.

\section{Discussion}

This retrospective study analyzed the efficacy of the parameters derived from the anterior and posterior corneal surfaces, keratoconus indices, thickness profile data, and data from enhanced elevation maps in discriminating eyes with $\mathrm{KC}$ from normal eyes. All parameters derived from the three maps showed statistically significant difference between keratoconus and normal group except the parameter of distance between thinnest point and apex. Previous studies found a mean distance between the apex and the thinnest point to range from 0.52 to $1.01 \mathrm{~mm}$ in healthy eyes and $0.78 \mathrm{~mm}$ in keratoconus eyes [9-12]. The mean values in this study in normal (0.82) and KC corneas (0.84) are comparable with previous reports. The differences in the reported values of distance between apex and thinnest location may be due to the high variability of study populations and the variety of instruments used in each study. Rüfer et al. also mentioned that repetition accuracy for the location of the thinnest point was rather poor, based on a high standard deviation of $x$ and $y$ coordinates, and attributed this to minor fixation deviations of the subject's eyes [13].

We further did ROC analysis to evaluate the predictive accuracy of these parameters in differentiating $\mathrm{KC}$ from normal corneas. Forty parameters derived from three maps were analysed. Out of 15 parameters from the topography maps thinnest corneal thickness (TCT) and Kmax showed excellent predictive accuracy. Being a well-known pathophysiological feature of $\mathrm{KC}$, corneal thickness is an important marker for both detection of $\mathrm{KC}$ and the severity level of the disease $[14,15]$. In this study, a cutoff value of $506 \mu$ had $89.0 \%$ sensitivity and $83.2 \%$ specificity for discriminating normal eyes from keratoconus. In previous studies, the cutoff point of TCT ranged from 489 to $493 \mu[7,16,17]$.

Nine parameters were studied from the topometric map and 5 of them showed excellent discrimination of keratoconus. These anterior surface topometric indices were ISV, IVA, KI, IHD, and Rmin. Table 3 shows abnormal topometric indices values of the manufacturer's user manual and this study. According to the manufacturer's user manual, an ISV value higher than 37 is considered abnormal (marked with yellow) and higher than 41 is pathological (marked with red)
[18]. The cutoff value for ISV in our study was 31.5 with $87.8 \%$ sensitivity and $96.2 \%$ specificity. An IVA value higher than 0.28 is considered abnormal and higher than 0.32 is pathological [18]. However, our cutoff value was 0.255 with a sensitivity and specificity of $91.3 \%$ and $96.4 \%$, respectively. A KI value higher than 1.07 is considered abnormal and/or pathological and IHD value higher than 0.014 is considered abnormal and higher than 0.016 is pathological while we found a cutoff value 1.055 with $91.0 \%$ sensitivity and $98.2 \%$ specificity for KI and 0.0175 with $90.0 \%$ sensitivity and $89.0 \%$ specificity for IHD. The average radius of the anterior corneal surface in normal corneas was reported to be $7.87 \pm 0.27 \mathrm{~mm}$ and it was considered abnormal and/or pathological if it is less than $6.71 \mathrm{~mm}[19,20]$. In this study, the average value of $R_{\min }$ was $7.55 \pm 0.27 \mathrm{~mm}$ in normal eyes and the cutoff value was 7.085 (96.8\% sensitivity and $80.7 \%$ specificity).

Fifteen parameters were studied from the BAD and 14 of them showed excellent discrimination. Difference in anterior and posterior elevation (FDE, BDE), F.Ele.Th, B.Ele.Th, ProgMin, ProgMax, ProgAvg, ARTmac, Df, Db, Dp, Dt, $\mathrm{Da}$, and $\mathrm{D}$ showed excellent predictive accuracy. The BAD is an integrated display in the Pentacam that combines elevation based and comprehensive pachymetric corneal evaluation in an all-inclusive display. The BAD displays each parameter and individually reports them as a standard deviation and then reports a final overall reading that is based on a regression analysis to maximize the separation of normal corneas from those with keratoconus [21]. Fam and Lim showed that anterior corneal elevation parameters are clinically relevant measures for detecting keratoconus and suspected keratoconus eyes [22]. Previous studies reported that anterior and posterior elevation were the most effective parameters for the diagnosis of keratoconus [23, 24]. In accordance with previous reports, the results of our study showed that anterior and posterior elevation parameters have excellent predictive accuracy in detecting keratoconus. The cutoff value for anterior elevation at the thinnest point in our study was 5.5 (91.3\% sensitivity and $97.4 \%$ specificity) and it was 13.5 (93.2\% sensitivity and $94.9 \%$ specificity) for posterior elevation which was comparable to that reported by Muftuoglu et al. but still lower than that reported by de Sanctis et al. [25, 26].

Corneal thickness spatial profile, percentage increase in thickness, percentage increase, and D parameters had high predictive accuracies in discriminating keratoconus from normal eyes. 
Ambrósio et al. introduced the analysis of corneal thickness spatial profiles and demonstrated significant differences in absolute thickness and percentage thickness increase as a function of distance from the thinnest point between normal and $\mathrm{KC}$ eyes $[27,28]$. The ART is a novel combined parameter that combines the thickness and pachymetric distribution and it was reported to have a sensitivity of $100 \%$ and a specificity of $96.5 \%$ in discriminating keratoconus from normal corneas [28]. The ARTmax provided the best combination of sensitivity (96.6\%) and specificity (90.7\%) in our study and the cutoff value of 311 was comparable with that reported by Ambrósio et al. [28].

D parameters compute the deviation from normal indices for the enhanced front and back elevations, for the thinnest value and for the pachymetric distributions. We found that all $\mathrm{D}$ parameters showed excellent accuracy in the discrimination of keratoconus.

Among all parameters studied, only IVA, KI, F.Ele.Th, B.Ele.Th, ARTmax, Dp, Da, and D showed excellent (>90\%) sensitivity and specificity in addition to excellent AUROC level.

One limitation of our study is that forme fruste keratoconus patients were not separated from keratoconus patients, so our work gives no threshold value for the detection of this condition.

In conclusion, this study aimed to evaluate the effectiveness of a large number of Pentacam parameters in the diagnosis of keratoconus in a fairly large sample size showing that the predictive accuracy of topographic, topometric, and BAD parameters was overall high but that the parameters of index of vertical asymmetry, keratoconus index, front and back elevation at the thinnest point, $A R T$, and $D$ values were the most sensitive and specific parameters for the diagnosis of keratoconus. These results may suggest that rather than relying on a single map, comprehensive analysis of topography, topometric indices, pachymetric data, and corneal height data in the Belin-Ambrósio enhanced ectasia display may provide useful information for improving the accuracy of keratoconus diagnosis and screening refractive candidates in a clinical setting.

\section{Abbreviations}

$\begin{array}{ll}\text { K: } & \text { Keratometry } \\ \text { TCT: } & \text { Thinnest corneal thickness } \\ \text { Cornea Vol: } & \text { Cornea volume } \\ \text { AC Vol: } & \text { Anterior chamber volume } \\ \text { ACD: } & \text { Anterior chamber depth } \\ \text { AC Angle: } & \text { Anterior chamber angle } \\ \text { ISV: } & \text { Index of surface variance } \\ \text { IVA: } & \text { Index of vertical asymmetry } \\ \text { KI: } & \text { Keratoconus index } \\ \text { CKI: } & \text { Center keratoconus index } \\ \text { IHA: } & \text { Index of height asymmetry } \\ \text { IHD: } & \text { Index of height decentration } \\ R_{\text {min }}: & \text { Minimum sagittal curvature } \\ \text { HOR Q: } & \text { Horizontal mean asphericity } \\ \text { VERT Q: } & \text { Vertical mean asphericity }\end{array}$

\begin{tabular}{|c|c|}
\hline FDE: & $\begin{array}{l}\text { Subtraction enhanced FBFS from } \\
\text { FBFSc }\end{array}$ \\
\hline BDE: & $\begin{array}{l}\text { Subtraction enhanced BBFS from } \\
\text { BBFS }\end{array}$ \\
\hline Dist.Apex-Th: & $\begin{array}{l}\text { Distance from corneal apex to } \\
\text { thinnest location }\end{array}$ \\
\hline F.Ele.Th: & Front elevation at thinnest location \\
\hline B.Ele.Th: & Back elevation at thinnest location \\
\hline ProgMin/Max/Avg: & Progress index \\
\hline ARTmax: & Ambrósio Relational Thickness \\
\hline Df: & $\begin{array}{l}\text { Deviation of front elevation } \\
\text { difference map }\end{array}$ \\
\hline Db: & $\begin{array}{l}\text { Deviation of back elevation } \\
\text { difference map }\end{array}$ \\
\hline Dp: & $\begin{array}{l}\text { Deviation of average pachymetric } \\
\text { progression }\end{array}$ \\
\hline Dt: & Deviation of minimum thickness \\
\hline $\mathrm{Da}$ & Deviation of ARTmax \\
\hline$D$ & Total deviation value. \\
\hline
\end{tabular}

\section{Conflict of Interests}

The authors declare that there is no conflict of interests regarding the publication of this paper. The authors do not have any proprietary interest in the products and drugs mentioned in this paper.

\section{References}

[1] Y. S. Rabinowitz, "Keratoconus," Survey of Ophthalmology, vol. 42, no. 4, pp. 297-319, 1998.

[2] Y. S. Rabinowitz, "Videokeratographic indices to aid in screening for keratoconus," Journal of Refractive Surgery, vol. 11, no. 5, pp. 371-379, 1995.

[3] D. M. Burns, F. M. Johnston, D. G. Frazer, C. Patterson, and A. J. Jackson, "Keratoconus: an analysis of corneal asymmetry," British Journal of Ophthalmology, vol. 88, no. 10, pp. 1252-1255, 2004.

[4] Z. Schlegel, T. Hoang-Xuan, and D. Gatinel, "Comparison of and correlation between anterior and posterior corneal elevation maps in normal eyes and keratoconus-suspect eyes," Journal of Cataract and Refractive Surgery, vol. 34, no. 5, pp. 789795, 2008.

[5] K. Miháltz, I. Kovács, Á. Takács, and Z. Z. Nagy, "Evaluation of keratometric, pachymetric, and elevation parameters of keratoconic corneas with pentacam," Cornea, vol. 28, no. 9, pp. 976980, 2009.

[6] R. Ambrósio Jr., R. S. Alonso, A. Luz, and L. G. C. Velarde, "Corneal-thickness spatial profile and corneal-volume distribution: tomographic indices to detect keratoconus," Journal of Cataract and Refractive Surgery, vol. 32, no. 11, pp. 1851-1859, 2006.

[7] O. Muftuoglu, O. Ayar, K. Ozulken, E. Ozyol, and A. Akinci, "Posterior corneal elevation and back difference corneal elevation in diagnosing forme fruste keratoconus in the fellow eyes of unilateral keratoconus patients," Journal of Cataract and Refractive Surgery, vol. 39, no. 9, pp. 1348-1357, 2013.

[8] G. A. Diamond, "What price perfection? Calibration and discrimination of clinical prediction models," Journal of Clinical Epidemiology, vol. 45, no. 1, pp. 85-89, 1992. 
[9] H. Hashemi, K. Yazdani, S. Mehravaran et al., "Corneal thickness in a population-based, cross-sectional study: the tehran eye study," Cornea, vol. 28, no. 4, pp. 395-400, 2009.

[10] P. T. Ashwin, S. Shah, S. Pushpoth, L. Wehbeh, and B. Ilango, "The relationship of central corneal thickness (CCT) to thinnest central cornea (TCC) in healthy adults," Contact Lens and Anterior Eye, vol. 32, no. 2, pp. 64-67, 2009.

[11] A. Keech, T. Simpson, and L. Jones, "Repeatability of pachymetry and thinnest point localization using a Fourierdomain optical coherence tomographer," Optometry and Vision Science, vol. 87, no. 10, pp. 736-741, 2010.

[12] V. Kaya, M. Karakaya, C. A. Utine, S. Albayrak, O. F. Oge, and O. F. Yilmaz, "Evaluation of the corneal topographic characteristics of keratoconus with Orbscan II in patients with and without atopy," Cornea, vol. 26, no. 8, pp. 945-948, 2007.

[13] F. Rüfer, S. Sander, A. Klettner, A. Frimpong-Boateng, and C. Erb, "Characterization of the thinnest point of the cornea compared with the central corneal thickness in normal subjects," Cornea, vol. 28, no. 2, pp. 177-180, 2009.

[14] D. P. Piñero, J. L. Alió, A. Alesón, M. E. Vergara, and M. Miranda, "Corneal volume, pachymetry, and correlation of anterior and posterior corneal shape in subclinical and different stages of clinical keratoconus," Journal of Cataract and Refractive Surgery, vol. 36, no. 5, pp. 814-825, 2010.

[15] S. Sahebjada, J. Xie, E. Chan, G. Snibson, M. Daniel, and P. N. Baird, "Assessment of anterior segment parameters of keratoconus eyes in an Australian population," Optometry and Vision Science, vol. 91, no. 7, pp. 803-809, 2014.

[16] Ö. Ö. Uçakhan, V. Çetinkor, M. Özkan, and A. Kanpolat, "Evaluation of Scheimpflug imaging parameters in subclinical keratoconus, keratoconus, and normal eyes," Journal of Cataract and Refractive Surgery, vol. 37, no. 6, pp. 1116-1124, 2011.

[17] S. M. Ahmadi Hosseini, F. Abolbashari, H. Niyazmand, and M. R. Sedaghat, "Efficacy of corneal tomography parameters and biomechanical characteristic in keratoconus detection," Contact Lens and Anterior Eye, vol. 37, no. 1, pp. 26-30, 2014.

[18] WaveLight, WaveLight Allegro Oculyzer 1074 User Manual, Wave Light, Erlangen, Germany, 2001.

[19] M. Dubbelman, H. A. Weeber, R. G. L. van der Heijde, and H. J. Völker-Dieben, "Radius and asphericity of the posterior corneal surface determined by corrected Scheimpflug photography," Acta Ophthalmologica Scandinavica, vol. 80, no. 4, pp. 379-383, 2002.

[20] A. J. Kanellopoulos and G. Asimellis, "Revisiting keratoconus diagnosis and progression classification based on evaluation of corneal asymmetry indices, derived from scheimpflug imaging in keratoconic and suspect cases," Clinical Ophthalmology, vol. 7, pp. 1539-1548, 2013.

[21] M. W. Belin and R. Ambrósio, "Scheimpflug imaging for keratoconus and ectatic disease," Indian Journal of Ophthalmology, vol. 61, no. 8, pp. 401-406, 2013.

[22] H.-B. Fam and K.-L. Lim, "Corneal elevation indices in normal and keratoconic eyes," Journal of Cataract \& Refractive Surgery, vol. 32, no. 8, pp. 1281-1287, 2006.

[23] K. Miháltz, I. Kovács, Á. Takács, and Z. Z. Nagy, "Evaluation of keratometric, pachymetric, and elevation parameters of keratoconic corneas with pentacam," Cornea, vol. 28, no. 9, pp. 976-980, 2009.

[24] K. Kamiya, R. Ishii, K. Shimizu, and A. Igarashi, "Evaluation of corneal elevation, pachymetry and keratometry in keratoconic eyes with respect to the stage of Amsler-Krumeich classification," British Journal of Ophthalmology, vol. 98, no. 4, pp. 459463, 2014.

[25] U. de Sanctis, C. Loiacono, L. Richiardi, D. Turco, B. Mutani, and F. M. Grignolo, "Sensitivity and specificity of posterior corneal elevation measured by Pentacamin discriminating keratoconus/subclinical keratoconus," Ophthalmology, vol. 115, no. 9, pp. 1534-1539, 2008.

[26] O. Muftuoglu, O. Ayar, K. Ozulken, E. Ozyol, and A. Akinci, "Posterior corneal elevation and back difference corneal elevation in diagnosing forme fruste keratoconus in the fellow eyes of unilateral keratoconus patients," Journal of Cataract \& Refractive Surgery, vol. 39, no. 9, pp. 1348-1357, 2013.

[27] R. Ambrósio Jr., R. S. Alonso, A. Luz, and L. G. C. Velarde, "Corneal-thickness spatial profile and corneal-volume distribution: tomographic indices to detect keratoconus," Journal of Cataract \& Refractive Surgery, vol. 32, no. 11, pp. 1851-1859, 2006.

[28] R. Ambrósio Jr., A. L. C. Caiado, F. P. Guerra et al., "Novel pachymetric parameters based on corneal tomography for diagnosing keratoconus," Journal of Refractive Surgery, vol. 27, no. 10, pp. 753-758, 2011. 


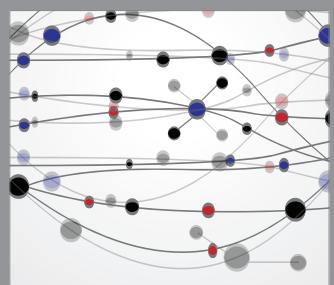

The Scientific World Journal
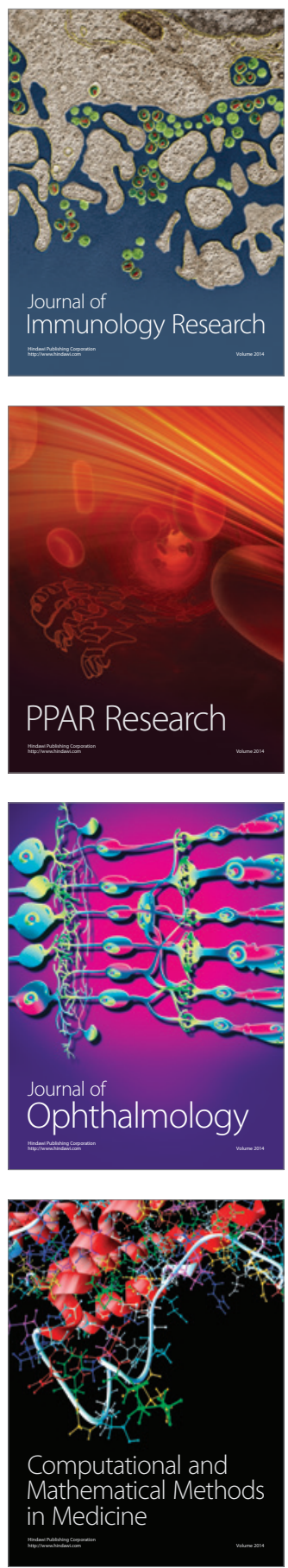

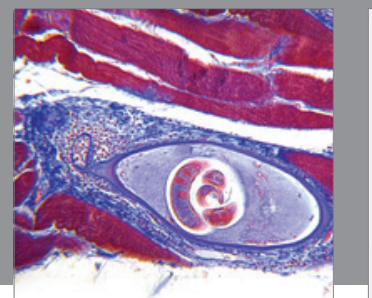

Gastroenterology

Research and Practice
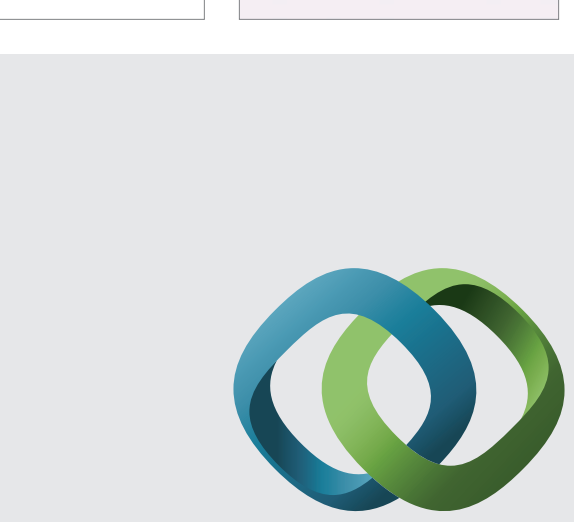

\section{Hindawi}

Submit your manuscripts at

http://www.hindawi.com
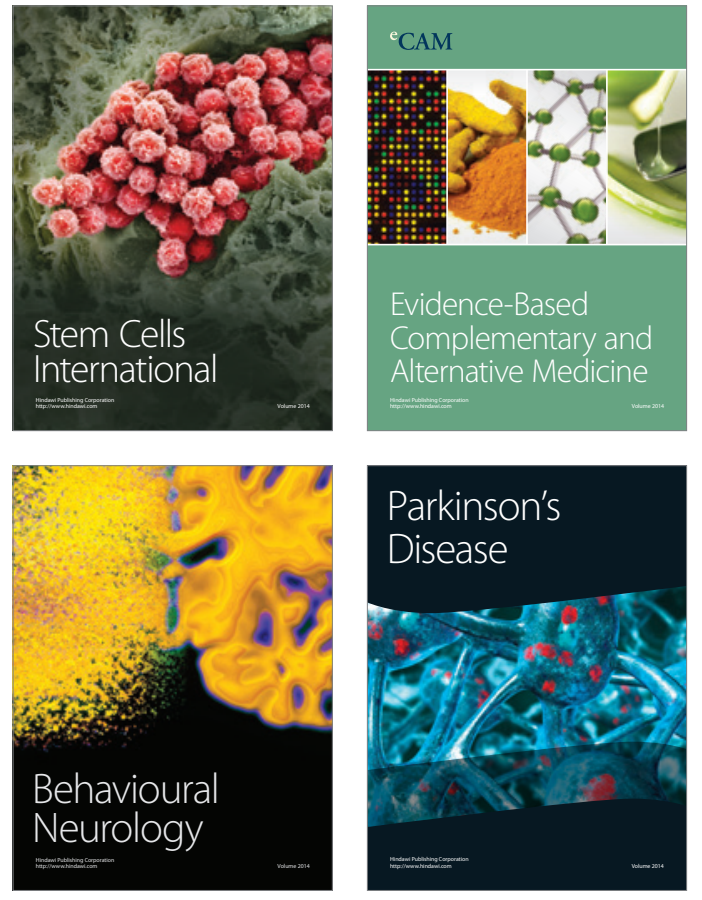
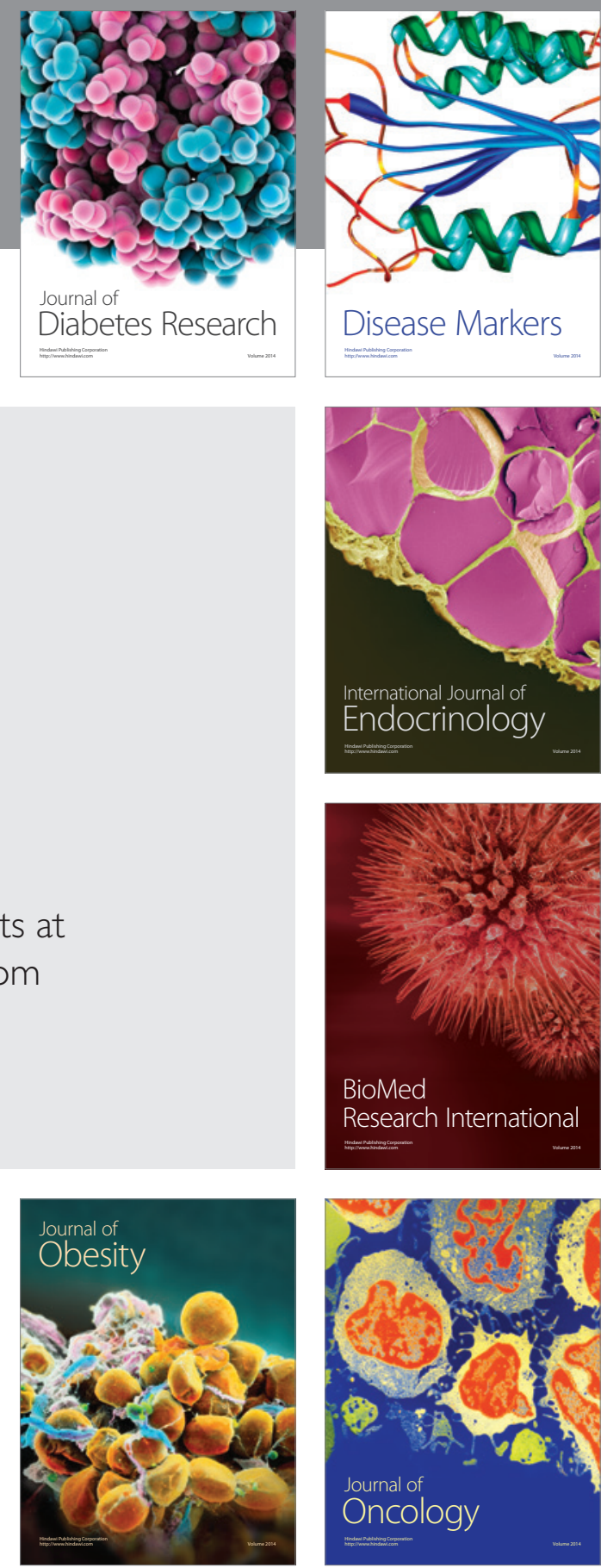

Disease Markers
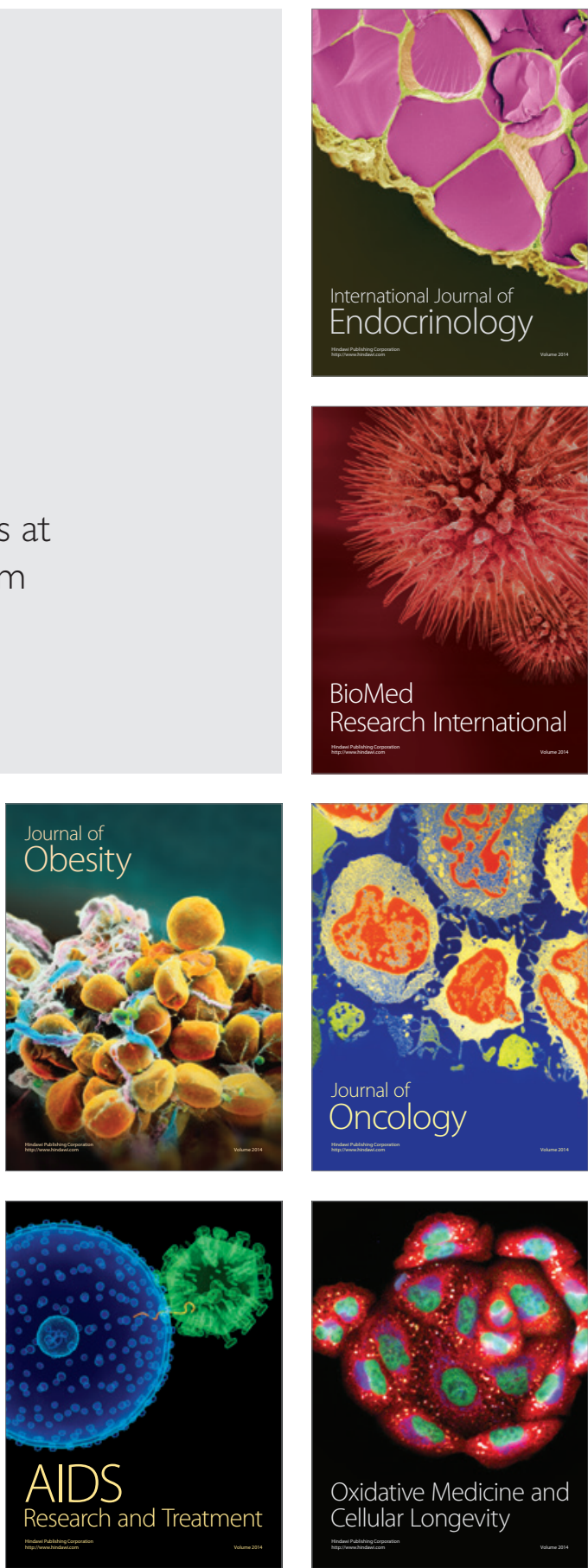